\title{
Article
}

\section{Can off-field 'brains' provide a competitive advantage in professional football?}

McCall, A., Davison, M., Carling, C., Buckthorpe, M., Coutts, A.J., and Dupont, G.

Available at https://clok.uclan.ac.uk/14717/

McCall, A., Davison, M., Carling, C. orcid iconORCID: 0000-0002-7456-3493, Buckthorpe, M., Coutts, A.J., and Dupont, G. (2016) Can off-field 'brains' provide a competitive advantage in professional football? British Journal of Sports Medicine, 50 (12). pp. 710-712. ISSN 0306-3674

It is advisable to refer to the publisher's version if you intend to cite from the work. http://dx.doi.org/10.1136/bjsports-2015-095807

For more information about UCLan's research in this area go to http://www.uclan.ac.uk/researchgroups/ and search for <name of research Group>.

For information about Research generally at UCLan please go to http://www.uclan.ac.uk/research/

All outputs in CLoK are protected by Intellectual Property Rights law, including Copyright law. Copyright, IPR and Moral Rights for the works on this site are retained by the individual authors and/or other copyright owners. Terms and conditions for use of this material are defined in the policies page.

\section{CLoK}

Central Lancashire online Knowledge www.clok.uclan.ac.uk

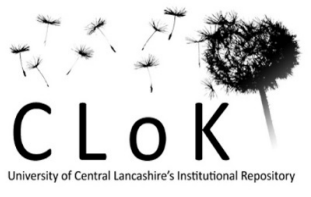


This is a pre-proof corrected manuscript, as accepted for publication, of an article published by BMJ Publishing Group in British Journal of Sports Medicine in June 2016, available online at: http://bjsm.bmj.com/content/50/12/710.extract

Title: Can off-field 'brains' provide a competitive advantage in professional football?

Authors: Alan McCall ${ }^{1,2}$, Michael Davison ${ }^{3}{\text { Chris } \text { Carling }^{4} \text {, Matthew Buckthorpe }}^{3}$, Aaron J Coutts ${ }^{5}$, Gregory Dupont ${ }^{2,6}$

\section{Institution:}

${ }^{1}$ Arsenal Football Club, Research \& Development Department, London, UK

${ }^{2}$ Edinburgh Napier University, Research \& Development Department, Edinburgh, UK

${ }^{3}$ Isokinetic Medical Group, FIFA Medical Centre of Excellence, London, UK

${ }^{4}$ Institute of Coaching and Performance, UCLAN, Preston, UK

${ }^{5}$ Faculty of Health, University of Technology Sydney (UTS), Australia

${ }^{6}$ University Lille Nord de France, EA7369, France.

\section{Corresponding author:}

\section{Alan McCall}

Arsenal Football Club

Bell Ln, London Colney

Hertfordshire, AL2 1DR

Tel: +33 651748266 - Fax: +33 320887363

Email: alan mccall@yahoo.co.uk 
1 Keywords: soccer, injury, performance

2

3 Word count: 799

4

5

6 
9 'Working-fast and working-slow' in sport describes the concept that practice and research can

10 be integrated to improve high-performance outcomes and improve professional practice.[1]

11 'Working-fast' is the task of the fast-thinking, intuitive practitioner operating on 'the ground'

12 at a frenetic pace, interacting with coaches, athletes and delivering the daily preparation

13 programme. 'Working-slow' is key for the team's deliberate, focused researcher acting as the 14 resident sceptic, operating behind the scenes on tasks that the 'fast-practitioner' may not have 15 time and/or skills to undertake. Such hidden, but important tasks include determining 16 measurement noise/error in performance tests, establishing proof of concept for new ideas and 17 ensuring validity of methods. Embedding research into the fast environment of high-

18 performance football may provide a competitive advantage using ethical and evidence-based methods.[1]

Football teams can learn from many of the world's largest technology companies.[2]

21 who embed research within their organisations to improve efficiency and enhance

22 productivity. Such a strategy is coined, 'Research and Development' (R\&D) and defined as:

23 'work directed toward the innovation, introduction and improvement of processes',[3]

24 However, to the current authors' knowledge, R\&D is not widely adopted in high-level

25 football teams.

Here we argue for professional football teams to embed R\&D in their daily activity to

27 improve' their processes relating to reducing injury-risk and optimising performance.

Innovation, introduction and improvement of processes using $R \& D$ 
31 In the fast-moving environment, practitioners combine data (e.g. training load, recovery,

32 screening) with their expert opinion to inform decisions on individual players. We suspect

33 these data are often not interrogated to the level that a researcher might aim for.[1]

34 Nevertheless, practitioners are expected to be innovative and often become early adopters of 35 new technology and techniques to gain competitive advantage (e.g. altitude training).[1] In-

36 house R\&D can inform judgements and decisions taken in the fast-working environment.

37 Remember that innovation is a sword with two-edges - it can also lead to impaired 38 performance.

Example 1 - what do repeated player measurements really mean?

High-performance practitioners undertake a multitude of measurements in their players (e.g. injury-screening, recovery/monitoring). However, it is impossible to know if changes are meaningful without knowing what noise (typical variation) surrounds the signal (actual change in measurements).[4] A R\&D programme can apply statistical methods to determine what is a real change for practitioners to act on.[6] Considering week-to-week variation (CV) and smallest-worthwhile change (SWC), we can determine 'real and meaningful' changes.[6,7] For example (Table 1), player 1 demonstrates a high week-to-week variation in recovery of isometric hamstring flexion and therefore requires greater change to detect anything meaningful. Player 2 with low week-to51 week CV requires a smaller reduction to be real (and thus, potentially at risk of injury). This concept applies to various monitoring, medical and performance measurement tools typically used in the professional football team setting. 
56 lower week-to-week variation for recovery of isometric hamstring flexion.

57

\begin{tabular}{|c|c|c|}
\hline $\begin{array}{l}\text { Isometric hamstring flexion force at } 90^{\circ} \\
\text { (dominant limb) }\end{array}$ & Player 1 & Player 2 \\
\hline Typical week-to-week variation (CV\%) & $13.8 \%(11.0-18.7)$ & $5.6 \%(4.5-7.7)$ \\
\hline Smallest Worthwhile Change (\%) & $2.8 \%$ & $1.1 \%$ \\
\hline Change in performance required to be real (\%) & $16.6 \%$ & $6.7 \%$ \\
\hline
\end{tabular}

63 While such confidence in data is imperative, the information must be translated so that it

64 influences practice (e.g. does the injury-screening tool detect injury risk, does the change in recovery-marker relate to real changes in performance?). Such analyses require specialised knowledge in analysing large datasets, which are time-consuming, and are not within the natural scope of practice for 'fast' practitioners, clinicians and strength and conditioning coaches.

Example 2 -is this technological aid valuable or just voodoo?

71 Teams are constantly faced with offers of new technologies and methods/procedures that

72 claim to accelerate recovery, reduce injuries and enhance performance. A teams' 'slow

73 worker' would investigate the legitimacy of such technologies. Using an adapted method

74 originally created to prescribe medication,[8] it is possible to assign graded-recommendations

75 (Figure 1) for new products or procedures in practice, based on scientific level and quality of evidence from research literature combined with expert opinion. This ensures that products or 

always at the forefront in professional football).

79

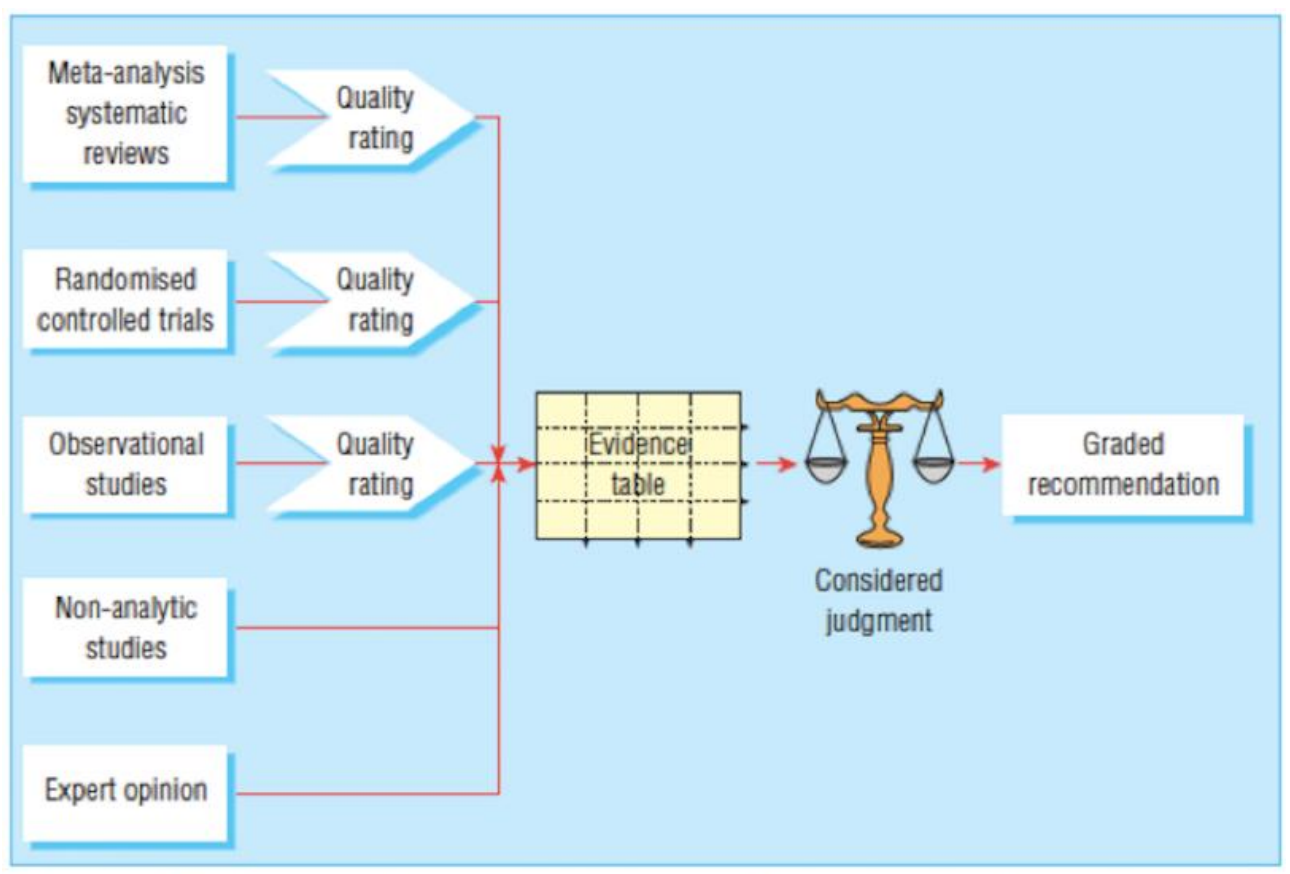

80

Overview of the process for developing and grading guideline recommendations

81 Figure 1: Proposed method to establish level of evidence and provide an overall graded recommendation for the introduction of a new product or process (reprinted with permission from Harbour and Miller, 2001[8]) (reprinted with permission, BMJ)

84

85 evidence to recommend).

89

Table 2: Assigning a graded recommendation: Consideration of Whole-Body Cryotherapy as a recovery modality using adapted evidence based medical guidelines[8] 


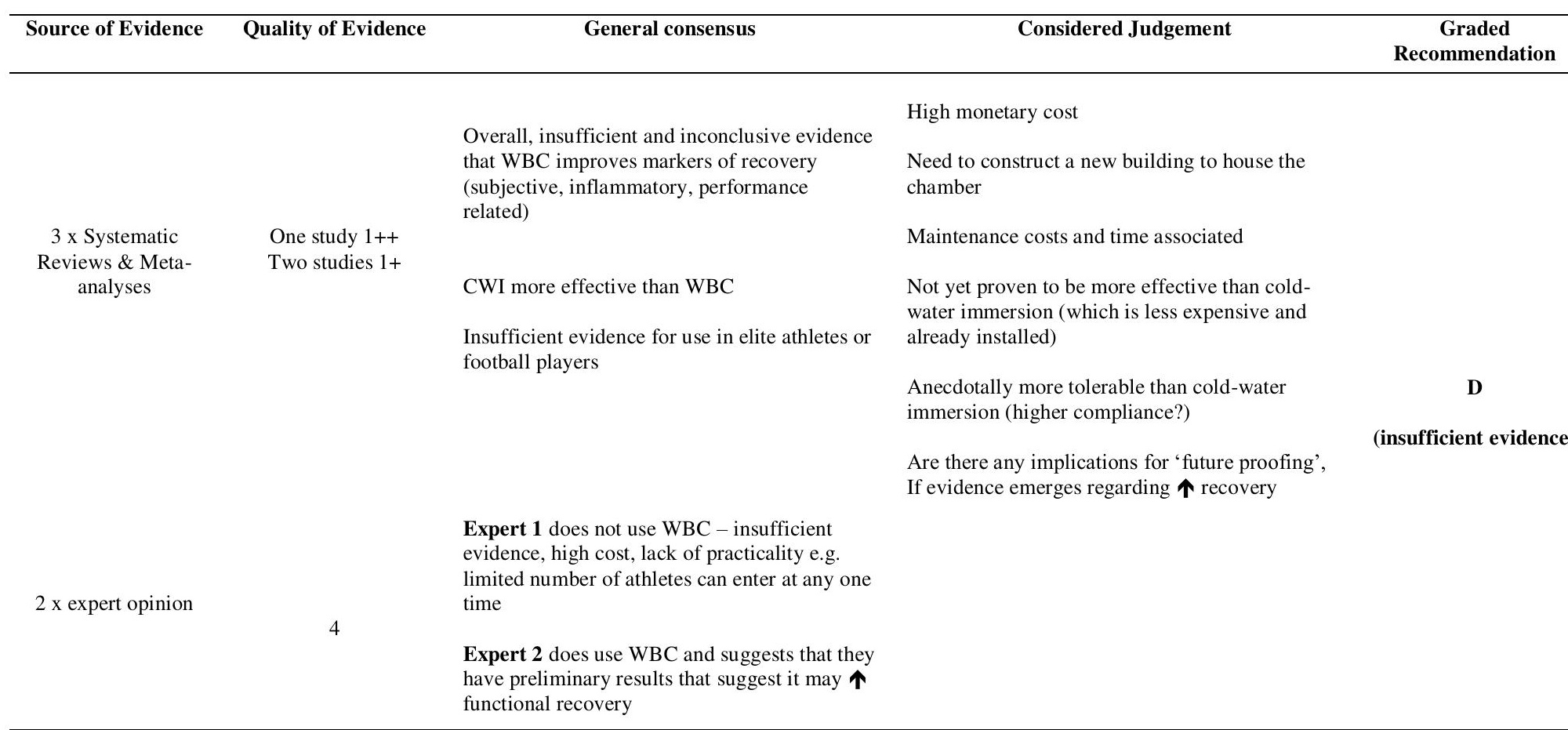

94 Quality of evidence ratings:

951 (Meta-analysis, systematic review of randomised control trials (RCT) or RCT)

962 (Systematic review of case control studies or cohort studies, case control, cohort studies)

973 (Non-analytic studies e.g. case reports, case series)

984 (Expert opinion)

$99++$ (High quality, very low risk of bias)

$100+$ (Well conducted, low risk of bias)

101 - (Low quality, high risk of bias)

102 Graded recommendations: A (High), B (Acceptable), C (Weak), D (insufficient evidence)

103 WBC - Whole-body cryotherapy

104 CWI - Cold-water immersion

105

106

108 The challenge: ensuring the slow-work impacts practice/performance

110 Successful preparation and acting on player-related recommendations in professional football

111 are highly dependent on 'buy in' from key-decision makers (coaches, players, CEOs). In the

112 fast-moving environment, these key-decision makers are concerned with simple 'yes/no'

113 answers (can the player train/play? will he/she suffer recurrent injury?) whereas the researcher

114 is concerned with 'what, why and how' of these issues. The ability to communicate relevant 
115 data with practical meaning is paramount. The R\&D role should provide translation of data

116 from complex analyses into clear messages to inform decision-making.

117

118 In summary, an effective way to optimise decision-making of the fast-intuitive practitioner

119 can be through embedding R\&D within the team, ensuring an ethical, valid and financially

120 prudent approach to the innovation, introduction and improvement of processes. Appropriate

121 delivery of information to team management is essential.

122

123 


\section{References}

125

126 1. Coutts, AJ. Working fast and working slow: The benefits of embedding research in High 127 performance sport. Int J Sports Physiol Perform 2016; 11:1-2.

128

129

2. Fortune magazine. The top 10 biggest $R \& D$ spenders worldwide.

130 http://fortune.com/2014/11/17/top-10-research-development/ Accessed 17 November 2015.

131

132

3. Oxford Dictionary. Definition of 'Research and Development.

133 http://www.oxforddictionaries.com/definition/english/research-and-development Accessed 28

134 January 2016.

135

136

4. Coutts AJ. In the age of technology, Occam's razor still applies. Int J Sports Physiol Perform 2014; 9:741.

138

139

5. Bahr et al. (2016) In press

140

141

6. Batterham A and Hopkins W. Making meaningful inferences about magnitudes. Int J Sports 142 Physiol Perf 2006; 1:50-57.

144 7. Hopkins W, Marshall S, Batterham A et al. Progressive statistics for studies in sports 145 medicine and exercise science. Med Sci Sports Exerc 2009; 41:3-12.

146

147 8. Harbour R and Miller J. A new system for grading recommendations in evidence based 148 guidelines. BMJ 2001; 323:334-336. 


\section{Figure Legend}

151

152 Figure 1: Proposed method to establish level of evidence and provide an overall graded

153 recommendation for the introduction of a new product or process (reprinted with permission

154 from Harbour and Miller, 2001[7]) (reprinted with permission, BMJ)

155

156

157 